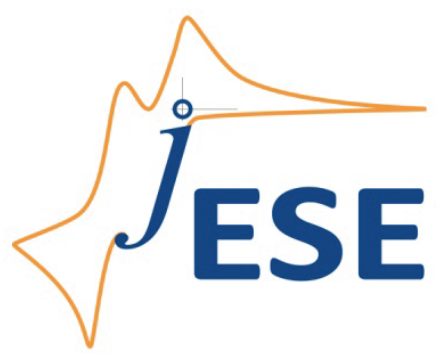

Open Access : : ISSN 1847-9286 www.jESE-online.org

Original scientific paper

\title{
Electrochemical extraction of oxygen using PEM electrolysis technology
}

\author{
BOULBABA ELADEB, CAROLINE BONNET, ERIC FAVRE and FRANÇOIS LAPICQUE
}

Laboratoire Réactions et Génie des Procédés, CNRS- Université de Lorraine, ENSIC, 1 rue Grandville, F-54001 Nancy, France

${ }^{\otimes}$ Corresponding Author: E-mail: francois.lapicque@ensic.inpl-nancy.fr; Tel.: 33 (0) 383175266

Received: March 13, 2012; Revised: July 12, 2012; Published: November 10, 2012

\begin{abstract}
Electrochemical extraction of oxygen from air can be carried out by chemical reduction of oxygen at the cathode and simultaneous oxygen evolution by water anode oxidation. The present investigation deals with the use of an electrolysis cell of PEM technology for this purpose. A dedicated $25 \mathrm{~cm}^{2}$ cell provided with a commercial water electrolysis MEA and titanium grooved plates has been designed for continuous operation at pressures close to the ambient level. The MEA consisted of a Nafion 117 membrane sandwiched between a Pt/C cathode and a non-supported Pt-Ir anode. Oxygen partial consumption in long-term runs was evaluated by analysis of the outlet air by gas chromatography, depending on the cell voltage - or the current density - and the excess in air oxygen fed to the cathode. Runs over more 50 hours indicated the relative stability of the components used for current densities ranging from 0.1 to $0.2 \mathrm{~A} \mathrm{~cm}^{-2}$ with high efficiency of oxygen reduction. Higher current density could be envisaged with more efficient MEA's, exhibiting lower overpotentials for oxygen evolution to avoid too significant degradation of the anode material and the membrane. Interpretation of the data has been carried out by calculation of the cathode current efficiency.
\end{abstract}

\section{Keywords}

Oxygen extraction; PEM electrolysis; electrode stability; Pt-Ir anode; current efficiency

\section{Introduction}

Extraction of oxygen from air can be used for various applications, as follows. For instance oxygen impoverished air reduces the oxidation content from the atmosphere over food for the sake of higher preservation in its packing. Lower oxygen contents in air also reduce the corrosion rate at non-noble metals pieces. Another potential application is the preparation of the gas phase to be injected to biological reactors - upon addition of carbon dioxide - for the possible growth of 
microorganisms such as bacteria, fungi or microalgae or undifferentiated cells of higher-grade vegetal organisms in dedicated bioreactors.

Various techniques for oxygen removal from a gas phase to be used for biological applications or food processing can be listed as follows. The easiest technique, which can be qualified as indirect, simply consists of adding of pure nitrogen into the air stream: the cost of pressured nitrogen renders the technique somewhat expensive for practical applications. Conventional, non electrochemical techniques for oxygen removal rely upon the following various principles: (i) oxygen combustion by a gas microburner, however other gases of significant safety or environment impact such as carbon monoxide or nitrogen oxides can be formed; (ii) selective reaction of oxygen upon addition of reducing agents e.g. sulfites that have been used for decades for food preservation: however the sulfate produced by oxygen oxidation of sulfite have to be removed from the medium; (iii) selective adsorption on a suitable compound which has nevertheless to be regenerated for its possible reuse; (iv) membrane separation of oxygen from carbon dioxide and nitrogen at temperatures close to ambient: however, because of the intermediate behaviour of oxygen in the three-species, this technique cannot be used for biological applications.

Besides, various electrochemical techniques can be used for oxygen extraction from an air flow, as reviewed by Winnick [1]. In a pioneering paper, Langer and Haldermann [2] showed that oxygen could be extracted from air and recovered in the form of pure oxygen in a two-compartment electrolytic cell, in the presence of acidic or alkaline solutions and separated by a conventional cationic membrane:

Cathode $\mathrm{O}_{2}+4 \mathrm{H}^{+}+4 \mathrm{e} \rightarrow 2 \mathrm{H}_{2} \mathrm{O}$

Anode $\quad 2 \mathrm{H}_{2} \mathrm{O} \rightarrow \mathrm{O}_{2}+4 \mathrm{H}^{+}+4 \mathrm{e}$

The equilibrium voltage of such a cell is nil, assuming similar conditions of $\mathrm{H}^{+}$activity and oxygen pressure in the two compartments; the cell voltage is the sum of the two overpotentials in absolute value- and the ohmic drop of the cell. The two reactions involved are nevertheless slow, even at platinum surfaces, and the cell voltage attains easily $1 \mathrm{~V}$ even at low current densities. Since then, the technique was improved by Wynween and Montgomery [3]. In the eighties, Fujita et al. [4] improved the efficiency of the technique by using a Nafion membrane, an air cathode whereas the anode was platinum particles deposited on the membrane surface: this technology derived from PEM fuel cell technology allowed current density up to $200 \mathrm{~mA} \mathrm{~cm}^{-2}$ for cell voltage at $1.4 \mathrm{~V}$ for continuous operation: the corresponding energy consumption for the oxygen extraction was near $4.7 \mathrm{kWh} \mathrm{kg}^{-1} \mathrm{O}_{2}$. It can be observed that the process consumes less energy than the conventional electrolysis, with specific energy consumption near $6.7 \mathrm{kWh} \mathrm{kg}^{-1} \mathrm{O}_{2}$ for a cell voltage of $2 \mathrm{~V}$, even though the current densities of the two processes differ quite a lot. More recently, General Electrics [5] developed an oxygen supply system for high-altitude aircraft relying upon similar technology: oxygen at high pressures could be produced with cell voltage claimed to be near $1 \mathrm{~V}$ at $125 \mathrm{~mA} \mathrm{~cm}^{-2}$.

The electrochemical separation of oxygen can be carried out upon specific diffusion in mixed, non stoichiometric oxides exhibiting oxygen vacancies in the lattice, as described in several patents [6-8]. The technology used derived from solid oxide cells: oxygen is reduced to $\mathrm{O}^{2-}$ ions at the cathode and migrates to the anode for back oxidation to oxygen; temperatures higher than $500{ }^{\circ} \mathrm{C}$ are required for sufficient diffusivity of $\mathrm{O}^{2-}$ ions in the non-stoichiometric oxide mixture. However the current density is usually below $100 \mathrm{~mA} \mathrm{~cm}^{-2}$. 
Oxygen extraction by its reduction to hydrogen peroxide on a graphite-based cathode through exchange of two electrons only was imagined by Tseung and Jasem [9]

$$
\text { Cathode } \mathrm{O}_{2}+\mathrm{H}_{2} \mathrm{O}+2 \mathrm{e} \rightarrow \mathrm{HO}_{2}^{-}+\mathrm{OH}^{-}
$$

As expected form the electron number, the energy consumption could be reduced to $2.7 \mathrm{kWh} \mathrm{kg}^{-1} \mathrm{O}_{2}$ in a concentrated $\mathrm{KOH}$ solution. Peroxide decomposes chemically to oxygen and peroxide on the surface of $\mathrm{NiCO}_{2} \mathrm{O}_{4}$ mesh, whereas oxygen is formed at the $\mathrm{NiCO}_{2} \mathrm{O}_{4}$ anode after

$$
\text { Anode } 2 \mathrm{OH}^{-} \rightarrow \frac{1}{2} \mathrm{O} 2+\mathrm{H}_{2} \mathrm{O}+2 \mathrm{e}
$$

Brillas et al. [10] developed the above technique by using carbon-polytetrafluorethylene air-fed cathode. Peroxide anions $\mathrm{HO}_{2}{ }^{-}$are formed at the carbon-based cathode, whereas oxygen evolution occurs at the anode by oxidation of both $\mathrm{HO}_{2}{ }^{-}$and $\mathrm{OH}^{-}$anions. Pure oxygen is produced with a voltage lower than in conventional water electrolyzers, because of the lower standard potential of $\mathrm{OH}^{-} / \mathrm{H}_{2} \mathrm{O}_{2}$, which further reduces the energy consumption. However, the current density is limited below $0.2 \mathrm{~A} \mathrm{~cm}^{-2}$ by the finite concentration of peroxide in the solution.

Recently, we demonstrated the use of a PEMFC for oxygen extraction, the anode reaction being hydrogen oxidation [11]. The technique was shown to be of relatively high efficiency, with current density up to $0.6 \mathrm{~A} \mathrm{~cm}^{-2}$, i.e. $0.015 \mathrm{~mol} \mathrm{O}_{2} \mathrm{~s}^{-1}$ per $\mathrm{m}^{2}$ membrane. Long-term tests confirmed the validity of the method, which however requires the presence of hydrogen to feed the fuel cell. To avoid this drawback, it was preferred to replace hydrogen oxidation at the anode by oxygen evolution. The present investigation deals with the use of an electrolysis cell of PEM technology involving reactions (1) and (2) at the electrodes. A dedicated $25 \mathrm{~cm}^{2}$ cell provided with a commercial water electrolysis MEA has been designed for operation at pressures close to the ambient level. Oxygen partial consumption in long term tests was evaluated by analysis of the outlet air, depending on the cell voltage - or the current density - and the excess in air oxygen fed to the cathode. Interpretation of the data has been conducted by calculating the cathode current efficiency.

\section{Experimental section}

\subsection{Electrochemical cell and measurement devices}

The $25 \mathrm{~cm}^{2}$ cell has been designed and built up from regular PEM technology. The cell consisted of two Ti bipolar plates being $10 \mathrm{~mm}$ thick: the flow pattern of serpentine type with five $1 \times 1 \mathrm{~mm}^{2}$ parallel channels with $1 \mathrm{~mm}$ broad edge was designed and machined by the mechanical workshop of the lab. The grooved part of the plate was covered by a $0.5 \mu \mathrm{m}$ gold layer by ion sputtering. Gas diffusion layer at the cathode was of carbon material (SGL 30 BC, UBZM, Germany) including a macroporous carbon fiber paper and a carbon black microporous layer (MPL), whereas a one $\mathrm{mm}$ thick high porosity Ti fleece was used at the anode. The MEA (Fumatech) designed for PEM water electrolysis, consisted in a 117 Nafion membrane, a Pt/C $\left(0.4 \mathrm{mg} \mathrm{cm}{ }^{-2}\right)$ cathode and a nonsupported Pt/Ir (0.45 $\mathrm{mg} \mathrm{cm}^{-2}$ ) anode (Figure 1).

All experiments were conducted at temperature levels ranging from 50 to $80^{\circ} \mathrm{C}$. Liquid water was driven to the anode compartment by a peristaltic pump at $5 \mathrm{~cm}^{3} \mathrm{~min}^{-1}$ and preheated before entering the cell. Purified compressed dry air at flow rate ranging from 20 to $200 \mathrm{STP} \mathrm{cm}^{3} \mathrm{~min}^{-1}$ was humidified in lab-made trickled bed at $\mathrm{RH}=62 \%$. The cell was operated either at fixed voltage or at controlled current density using a PGSTAT 30 Autolab potensiostat connected to a 20 Amp. Autolab booster. 


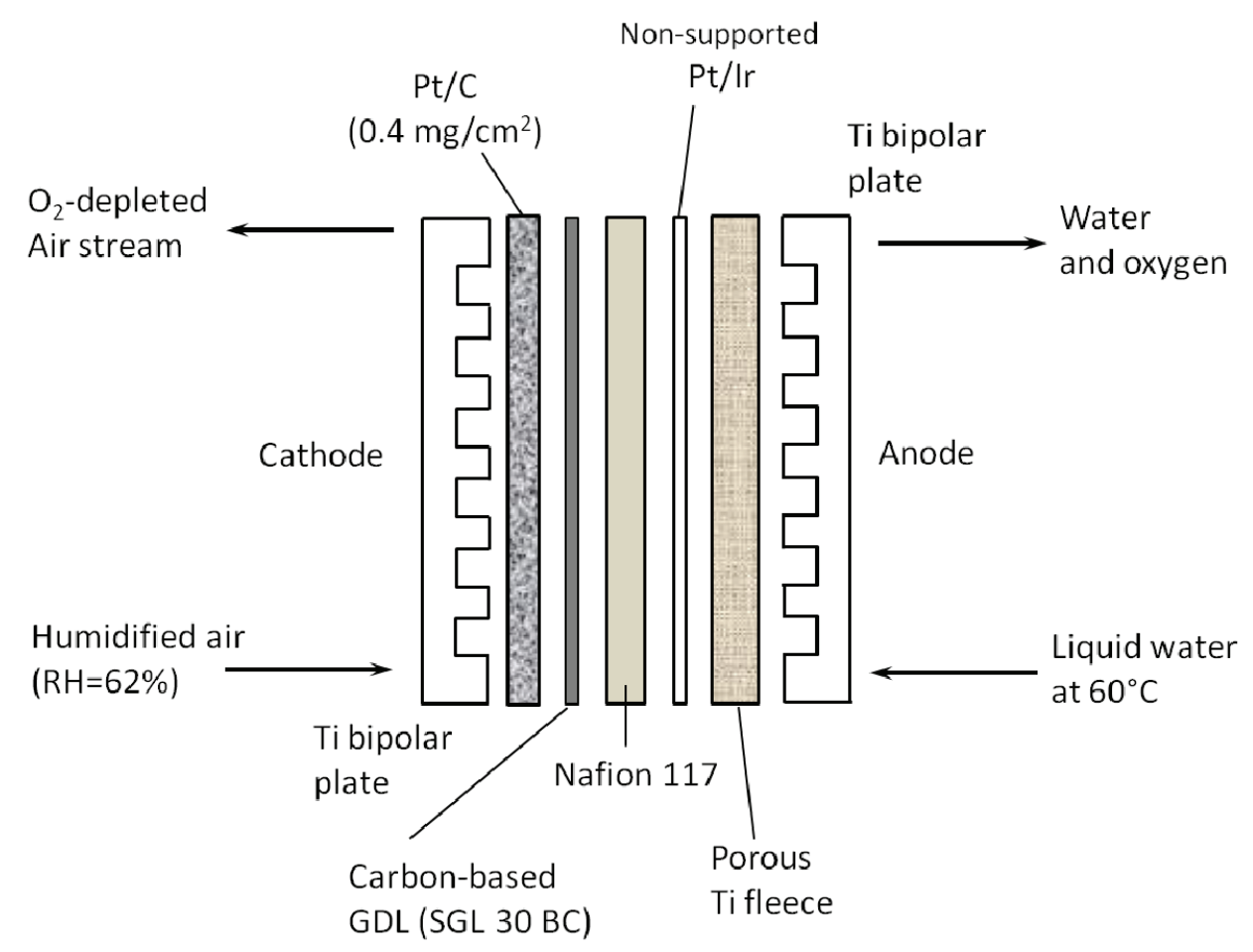

Figure 1. Schematic view of the $25 \mathrm{~cm}^{2}$ cell for oxygen extraction

Prior to its use for oxygen extraction, the MEA was run up by carrying out water electrolysis at $80^{\circ} \mathrm{C}$ : the anode was fed with hot water and nitrogen at $40 \mathrm{STP} \mathrm{cm}^{3} \mathrm{~min}^{-1}$ was fed to the cathode. As recommended by the supplier the MEA was conditioned by 24 hour long operation at $2.0 \mathrm{~V}$ for maturation of the anode Ir/Pt catalyst.

\subsection{Current versus voltage measurements}

Current density vs. voltage curve was established either in potensiostatic or in galvanostatic modes, so that the cell voltage was below $1.4 \mathrm{~V}$ for long term runs. Because the reactions of interest are oxygen reduction and evolution, the two electrode potentials are distributed around the equilibrium potential of $\mathrm{H}_{2} \mathrm{O} / \mathrm{O}_{2}$ couple. Moreover the two reactions are relatively slow processes and exhibit absolute overpotentials in the same order of magnitude, it can therefore be estimated that the maximal cell voltage corresponds to anode potentials in the order of $1.8 \mathrm{~V}$ vs. NHE i.e. in a domain where corrosion phenomena at the anode can become significant and affect the stability of the anode catalyst. Most measurements were carried out with air but oxygen was also used for comparison.

\subsection{Oxygen extraction runs and gas analysis}

Oxygen extraction was achieved through numerous runs conducted at fixed current density for which the cell voltage was below $1.4 \mathrm{~V}$ as justified above. Taking into account Faraday's law and the oxygen content in air $\left(y_{\mathrm{O}_{2}}^{\text {in }}=0.21\right)$, the inlet oxygen flow rate was large enough for all runs. The cell voltage at fixed current and air flow rate was monitored for lapses of time ranging from 4 to 24 hours: in most cases, the voltage attained a steady value within ten to thirty minutes.

The gas leaving the cathode was stored in a $400 \mathrm{~cm}^{2}$ polymeric sampling bag. This bag has been thoroughly emptied first, the outlet was then sampled for a couple of minutes and the bag was purged again. The second, longer sampling procedure for analysis was then achieved. After sufficient filling, the sampling gas was shut. The decrease in temperature to the ambient level was 
the cause of water condensation and the bag slightly shrunk. The ambient temperature, $T_{\mathrm{amb}}$, recorded for all runs ranged from 19 to $27^{\circ} \mathrm{C}$. Analysis of the gas containing in the bag, i.e. nitrogen, oxygen and slight amount of water vapor was carried out off line by gas chromatography using a molecular sieve microcolumn with a TCD detector in the $\mu G C$ equipment (Varian 490 GC). Three replicate analyses were conducted for each sample. The TCD detector was calibrated by analysis of six synthetic air-nitrogen mixtures of oxygen concentration perfectly known and ranging from 5 to $21 \mathrm{vol}$. \%. The vapor amount in the gas mixture at $T_{\text {amb }}$ was estimated using Antoine's law:

$$
\log P_{\mathrm{H}_{2} \mathrm{O}}=5.20389-\frac{1737.93}{T_{\mathrm{amb}}-39.485}
$$

where the partial pressure of water is expressed in Atm and $T_{\mathrm{amb}}$ is in $\mathrm{K}$. The composition of the dry outlet could then be deduced from $y_{\mathrm{H}_{2} \mathrm{O}}$.

\section{Experimental results and interpretation}

\subsection{Electrochemical behavior of the cell}

Steady values of the current or the voltage - depending on the electrical mode - were usually obtained within 15 minutes or so and for voltammetric measurements the voltage or current level was changed every 30-60 minutes. The MEA response could slightly depend on the long-term run carried out immediately before the measurement. Temperature was shown to exert a moderate effect (data not shown) and the results presented here were obtained at $60^{\circ} \mathrm{C}$.

At a given voltage gas flow rate exerted also a moderate influence on the cell current at a given cell voltage, as exemplified by Figure 2. Over a given flow rate depending on the current density, the effect is however of reduced importance. The observed phenomenon probably expresses the partial control by oxygen diffusion from the air fed to the cathode.

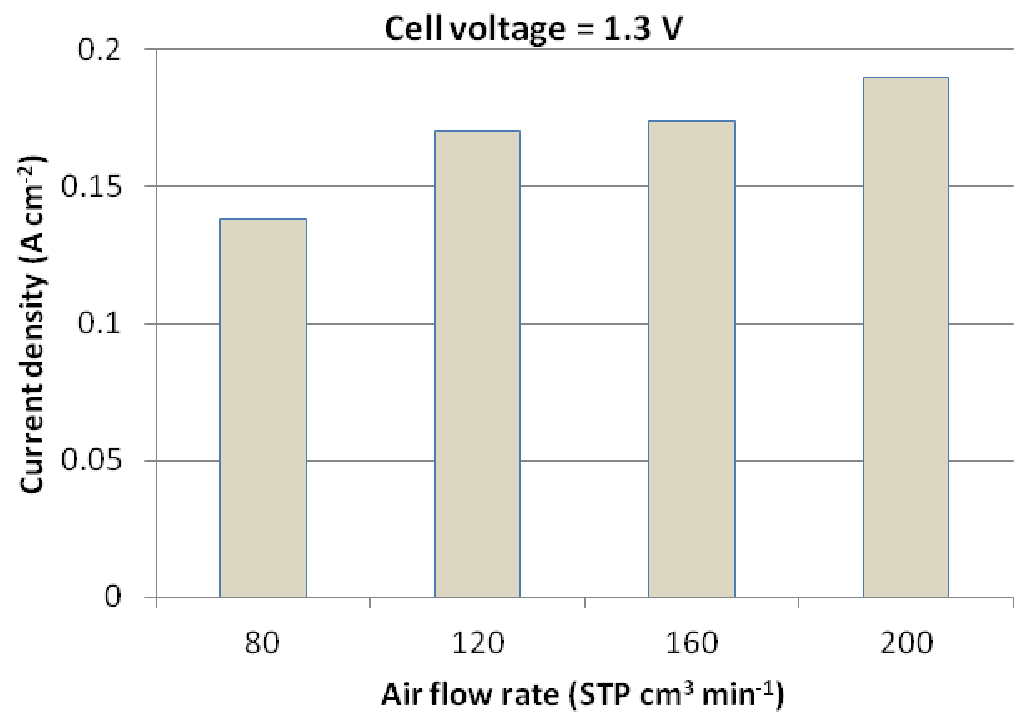

Figure 2. Effect of the air flow rate on the current density recorded at fixed cell voltage.

As expected, current density is an increasing function of the cell voltage (Figure 3). Feeding the cell with pure oxygen largely increases the performance of the cell, with for instance a current density twofold larger with pure oxygen than upon air feed at 1V. In comparison to what occurs with air pure oxygen accelerates charge transfer rates in both oxygen reduction and evolution, 
while suppressing the gas-side mass transfer occurring in the presence of air nitrogen. Current density up to $0.34 \mathrm{~A} \mathrm{~cm}^{-2}$ could be measured at $1.2 \mathrm{~V}$ with pure oxygen. The voltammetric data were compared to those obtained by Langer [2] or by Fujita [4] in Figure 3. In spite of the different $i-V$ profiles reported, the available current densities are in the same order of magnitude over $1 \mathrm{~V}$, also with better performance with pure oxygen. The differences between the three sources of data can be explained by the different features of the electrochemical cells: in addition to the likely different ohmic resistances, the electrodes differed a lot, in particular the anode, consisting of deposited Pt in the quoted papers and a Pt-Ir mixture in the present investigation.

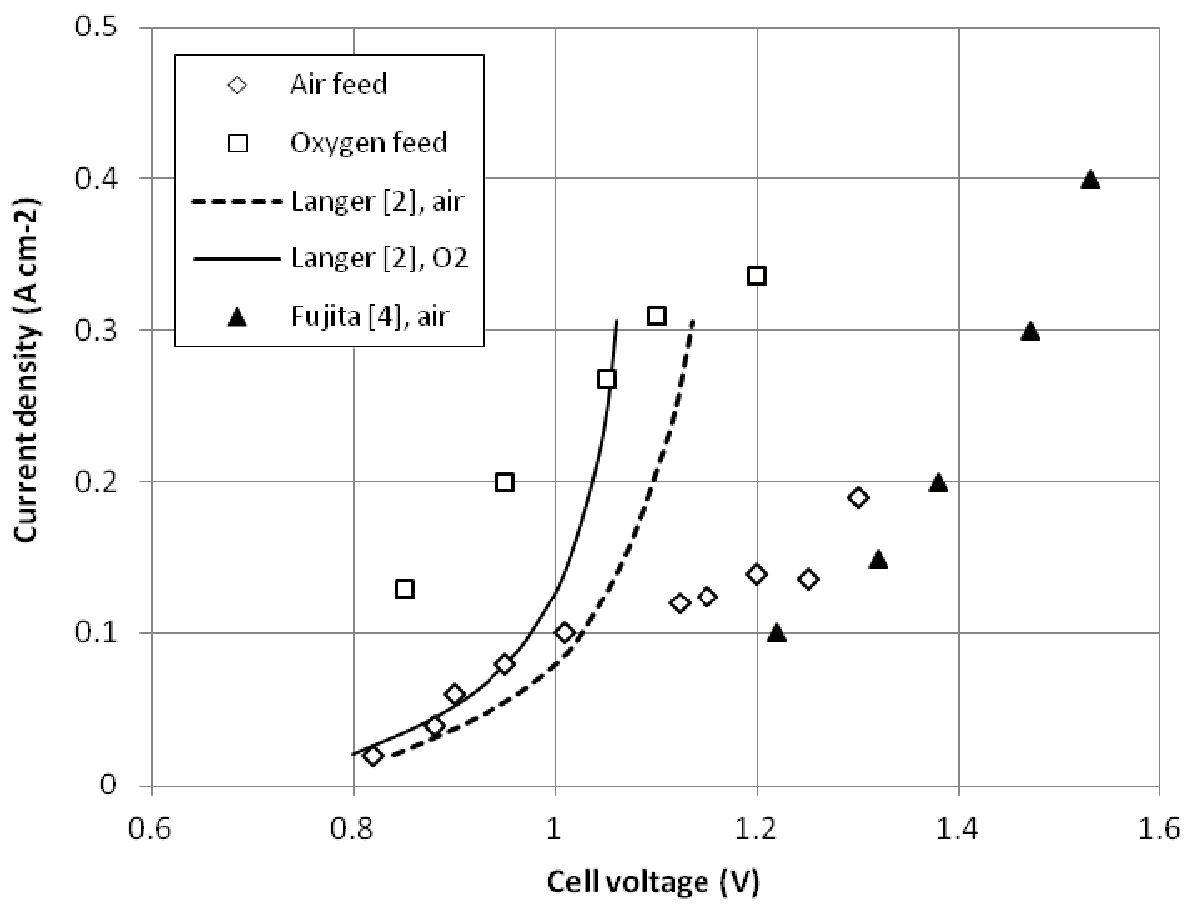

Figure 3. Current density versus cell voltage at steady state. Present work with air at 200 STP $\mathrm{cm}^{3} \mathrm{~min}^{-1}$ and oxygen at 120 STP $\mathrm{cm}^{3} \mathrm{~min}^{-1}$; comparison with literature data.

Besides, the cell behaviour in long term runs was examined during oxygen extraction runs. As shown by Figure 4 for fixed values of the cell voltage, the current monitored remained at a stable level for periods up to 50 hours.

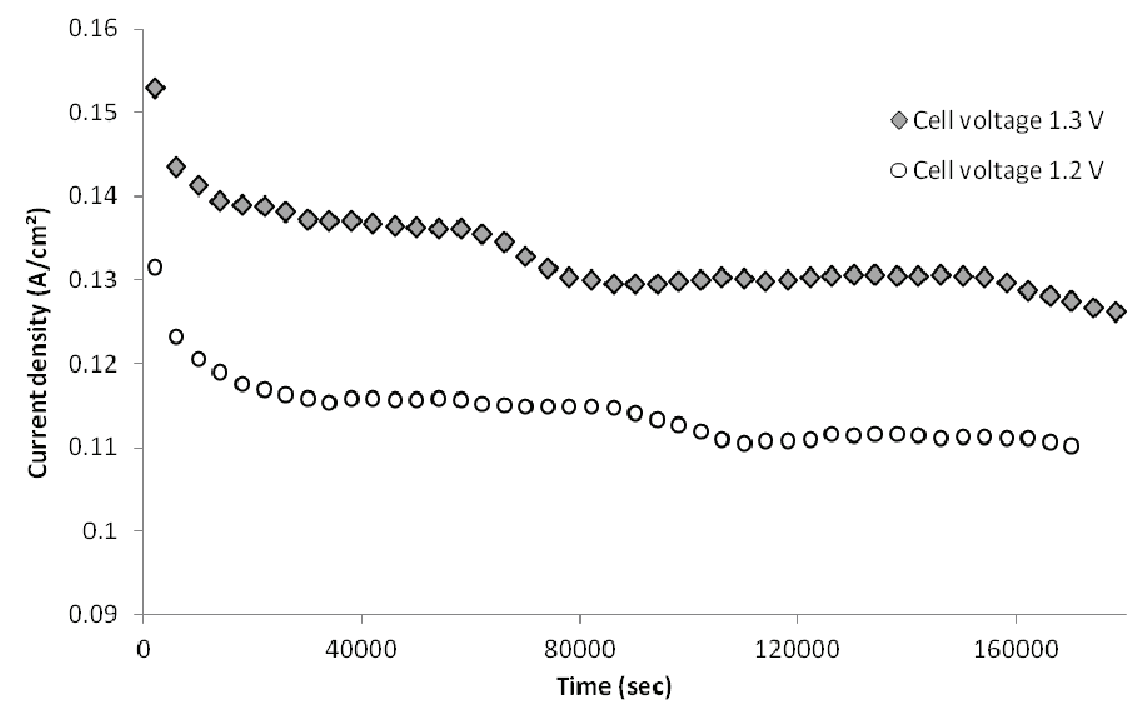

Figure 4. Current density in the oxygen extraction cell operated at fixed voltage. 


\subsection{Model of the cell oxygen extraction}

A simple zero-D model has been written for the cathode compartment of the cell. The inlet variables are the molar flow rate of dry air $F_{\text {air }}^{\text {in }}$ and the cell current $I$, whereas outlet variables are the molar flow rate of oxygen $F_{\mathrm{O}_{2}}^{\text {out }}$ and the temperature of the sampling gas, $T_{\text {amb }}$ : water was assumed to be at vapor-liquid equilibrium at $T_{\text {amb }}$. Faraday's law is written for oxygen consumption at the cathode according to reaction (1):

$$
F_{\mathrm{O}_{2}}^{\text {out }}=F_{\mathrm{O}_{2}}^{\text {in }}-\frac{\Phi l}{4 \mathfrak{I}}
$$

where $\Phi$ is the current efficiency of oxygen reduction and $\mathfrak{I}$ is the Faraday's constant. The inlet oxygen flow rate is related to the inlet air flow as follows:

$$
F_{\mathrm{O}_{2}}^{\text {in }}=F_{\text {air }}^{\text {in }}-F_{\mathrm{N}_{2}}^{\text {in }}=F_{\text {air }}^{\text {in }} y_{\mathrm{O}_{2}}^{\text {in }}
$$

where fraction $y_{\mathrm{O}_{2}}^{\text {in }}$ refers to the oxygen content in air. The oxygen molar fraction in the sampling bag is defined as:

$$
y_{\mathrm{O}_{2}}^{\text {out }}=\frac{F_{\mathrm{O}_{2}}^{\text {out }}}{F_{\mathrm{t}}^{\text {out }}}
$$

where subscript $t$ refers to the total number of moles in the gas, covering nitrogen, oxygen and water vapor. Finally the total molar flow rate of gas is related to the flow of dry gas and the vapor molar fraction in the bag:

$$
F_{\mathrm{t}}^{\text {out }}=\frac{F_{\text {air }}^{\text {out }}}{1-y_{\mathrm{H}_{2} \mathrm{O}} T_{\mathrm{amb}}}=\frac{F_{\text {air }}^{\text {in }}-\frac{\Phi l}{4 \mathfrak{I}}}{1-y_{\mathrm{H}_{2} \mathrm{O}} T_{\mathrm{amb}}}
$$

For the sake of simplicity, the ambient temperature is no more mentioned in the following. The fraction of vapor in the sampled gas was calculated by Antoine's law. Finally, the stoichiometric factor $\lambda$ of fed air oxygen related to the flow of oxygen consumed by reaction (1) with a current efficiency at unity is defined by the relation:

$$
F_{\mathrm{O}_{2}}^{\text {in }}=y_{\mathrm{O}_{2}}^{\text {in }} F_{\text {air }}^{\text {in }}=\lambda \frac{1}{4 \mathfrak{I}}
$$

From relations (6) to (9) the current efficiency of oxygen reduction $\Phi$ is expressed as follows:

$$
\Phi=\lambda \frac{1-y_{\mathrm{H}_{2} \mathrm{O}}-\frac{y_{\mathrm{O}_{2}}^{\text {out }}}{y_{\mathrm{O}_{2}}^{\text {in }}}}{1-y_{\mathrm{O}_{2}}^{\text {out }}-y_{\mathrm{H}_{2} \mathrm{O}}}
$$

For current efficiency equal to unity, the molar fraction of the oxygen in the sampling bag can be directly expressed as a function of operating parameter $\lambda$ as:

$$
y_{\mathrm{O}_{2}}^{\text {out }}=\frac{\lambda-1}{\frac{\lambda}{y_{\mathrm{O}_{2}}^{\text {in }}}-1}\left(1-y_{\mathrm{H}_{2} \mathrm{O}}\right)
$$




\subsection{Experimental data and comparison with model predictions}

The oxygen molar fractions determined by gas chromatography are compared to the values predicted by eq. (11) in Figure 5, considering the actual $T_{\text {amb }}$ value. Good agreement between theory and practice is generally observed, even though the predicted line is slightly below the experimental data, indicating that the current efficiency could be somewhat lower than unity. For very large $\lambda$ values, corresponding to large excess in oxygen, air is only slightly depleted in oxygen and the outlet gas fraction of oxygen is little different from the inlet value. Conversely, with low excess of oxygen, high abatement of oxygen from the fed air can be obtained, as expected.

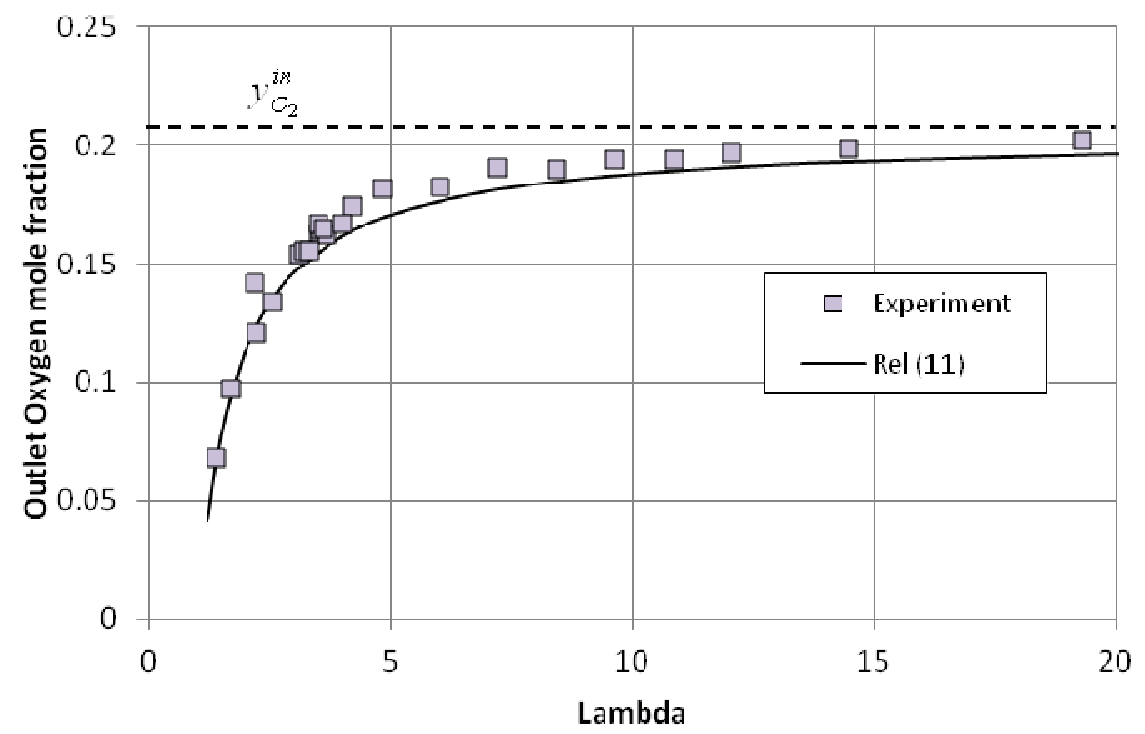

Figure 5. Oxygen molar fraction at the outlet of the cell versus the stoichiometric factor of air oxygen $\lambda$

Finally, because the outlet molar fractions of oxygen are in the same order of magnitude as the inlet fraction, in particular for large excess in fed air, the uncertainty in the determination of the current efficiency had to be estimated. The related calculations reported in the appendix show that high values of the current and moderate values for stoichiometric factor are favorable for higher accuracy in the determination of $\Phi$ : although the inlet flow rate of air could be moderate, the outlet molar fraction of oxygen is noticeably different from the inlet fraction, which prevails on the overall estimate for the uncertainty. On the contrary, for large $\lambda$ values, the outlet molar fraction of oxygen is little below the inlet fraction and, from the expressions of terms $A$ and $B$, the determination of the current efficiency is little accurate, with uncertainty exceeding $30 \%$.

The variations of the current efficiency with the stoichiometric factor of air oxygen and current density are shown in Figure 6 and 7 respectively, in the form of the maximum and the minimum estimates for each experiment. In spite of a significant dispersion, the data clearly show that the current efficiency is somewhat lower than unity.

The separate analysis of the effect of operating conditions on the current efficiency is rendered uneasy because of the large dispersion of the data in the representations ( $\Phi$ vs. $\lambda$ ) or ( $\Phi$ vs. $i$ ) in Figure 6 and 7. This apparent dispersion is mainly caused by the uncertainty in the determination of the current efficiency but also by the slight interaction between the two parameters. Nevertheless the stoichiometric factor of air oxygen exerts a negative influence on the current efficiency (Figure 6) whatever the current density applied. The positive effect of current density on $\Phi$ appears clearly with very little effect from $\lambda$ (Figure 7): for current density over $100 \mathrm{~mA} \mathrm{~cm}^{-2}$, the current efficiency is near or larger than 0.9 , which is promising for the investigated process. 


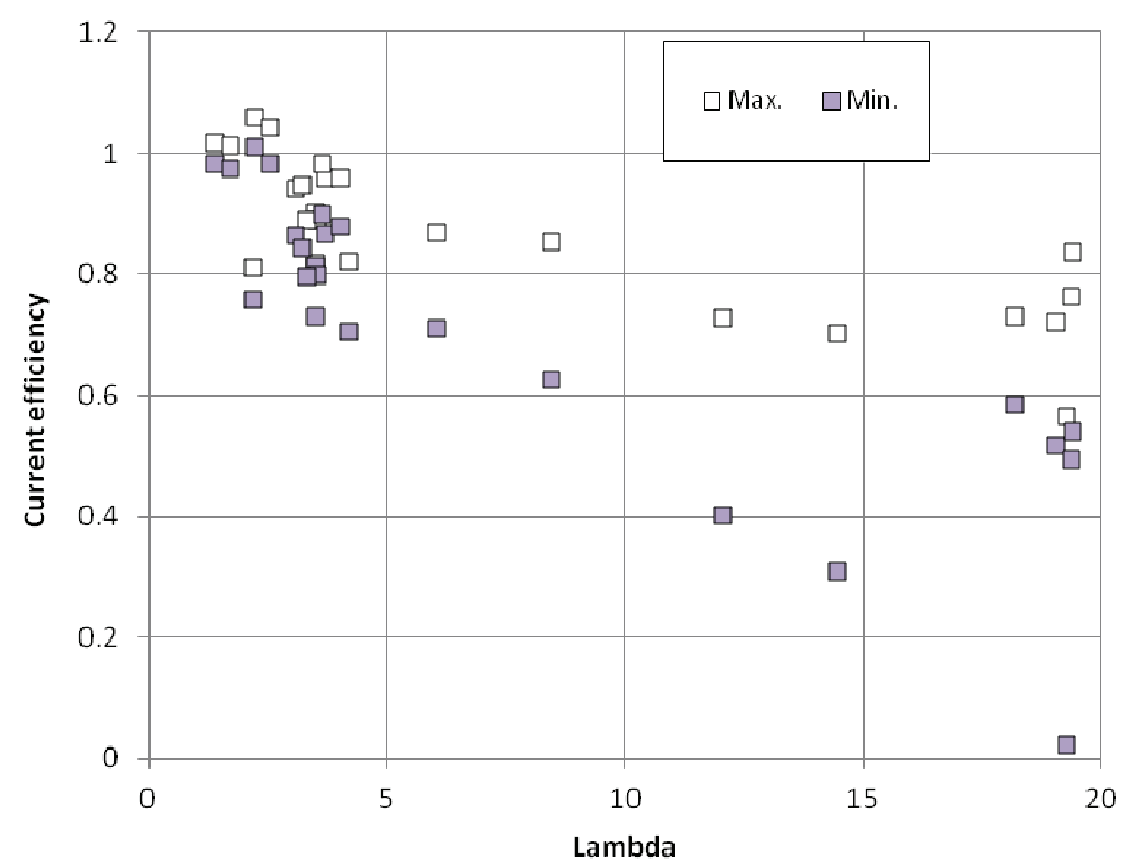

Figure 6. Current efficiency for oxygen reduction in the cell versus stoichiometric factor $\lambda$ : maximum and minimum estimates

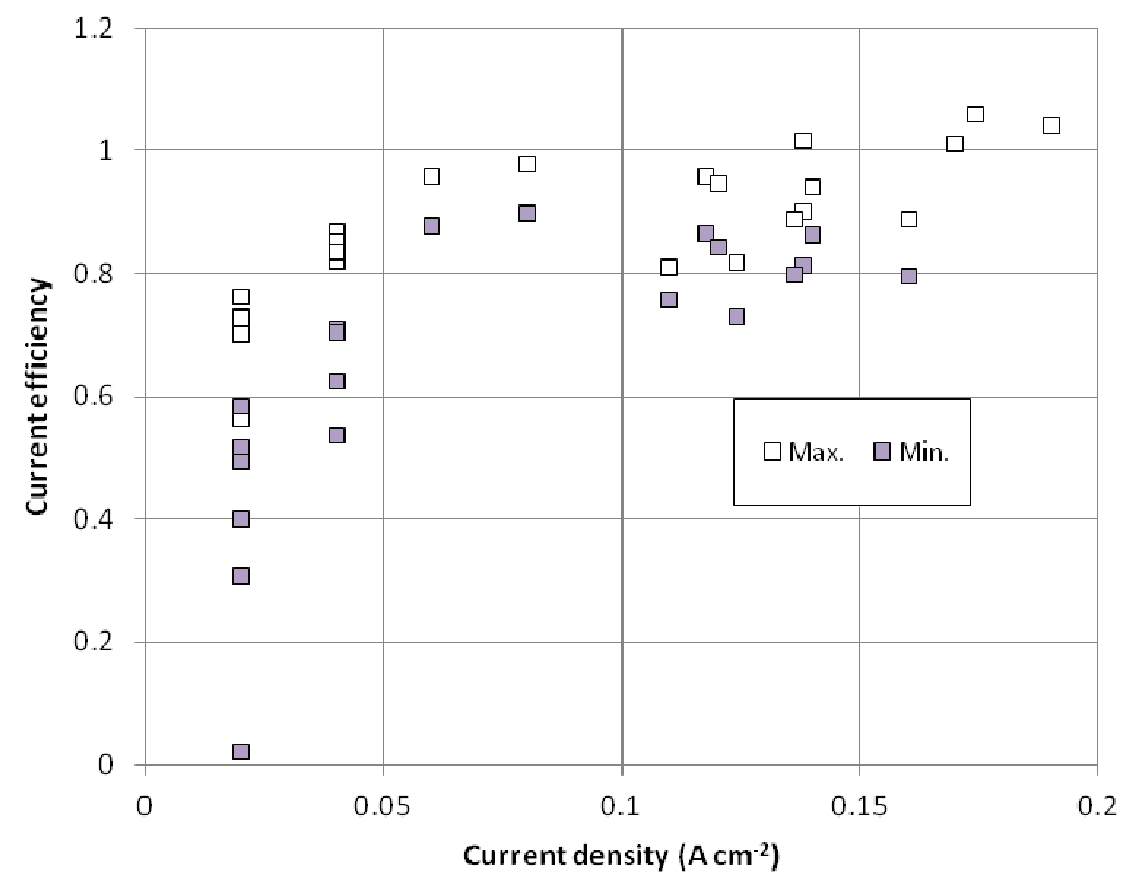

Figure 7. Current efficiency for oxygen reduction in the cell versus the current density: maximum and minimum estimates

\section{Conclusions and significance}

The validity of the oxygen extraction using PEM electrolysis technology has been validated in long term runs for current density up to $200 \mathrm{~mA} \mathrm{~cm}^{-2}$, with a cell voltage near $1.3 \mathrm{~V}$. Assuming that the reductive extraction is carried out with a current efficiency of $90 \%$, the corresponding energy consumption can be estimated to be near $4.4 \mathrm{kWh} \mathrm{kg}^{-1} \mathrm{O}_{2}$. Although the state of health of the PEM 
electrodes could not be evaluated by measurements of the electrode active surface [12], as done for PEMFC, no real decay in activity could be observed after more than 400 hour tests with the same MEA.

Considering the current progresses in water electrolysis technology, the current efficiency can be expected to attain $100 \%$, which would result in energy consumption near $4 \mathrm{kWh} \mathrm{kg}^{-1} \mathrm{O}_{2}$. Besides, the current improvement in the electrodes of PEM electrolysers is to allow substantial reduction in cell voltage. However, to our point of view, the main advantage offered by PEM electrodes is that the cathode reaction involving air oxygen should be carried out with current density to $1 \mathrm{~A} \mathrm{~cm}^{-2}$, provided that the cell voltage does not exceed $1.4 \mathrm{~V}$ to limit degradation issues at an acceptable level: progress in electrolysis MEA has to be achieved for this purpose. In contrast, the reduction from a liquid phase as done through the peroxide route cannot be conducted for current densities over 100 or $200 \mathrm{~mA} \mathrm{~cm}{ }^{-2}$. Although the PEM technique is not to allow lower energy consumption, higher production rates can be expected.

Long-term tests will be carried out at larger current densities, i.e. higher cell voltages, together with investigation of ageing phenomena, to evaluate the highest current density offered by the technique. Further work has to be done by improving developing electrode materials exhibiting faster kinetics for both oxygen reduction and evolution.

Acknowledgements: The authors are indebted from Region Lorraine and Institut Carnot ICEEL which funded the investigation cost and B. Eladeb's PhD grant.

\section{Appendix: Uncertainty in determination of the current efficiency}

Relation (10) shows that efficiency $\Phi$ is a function of parameters or variables $\lambda, y_{\mathrm{O}_{2}}^{\text {out }}$ and $y_{\mathrm{H}_{2} \mathrm{O}}$. The differential of the current efficiency was expressed as a function of partial derivatives with respect to the three above variables:

$$
\mathrm{d} \Phi=\left(\frac{\partial \Phi}{\partial \lambda}\right) \mathrm{d} \lambda+\left(\frac{\partial \Phi}{\partial y_{\mathrm{O}_{2}}^{\text {out }}}\right) \mathrm{d} y_{\mathrm{O}_{2}}^{\text {out }}+\left(\frac{\partial \Phi}{\partial y_{\mathrm{H}_{2} \mathrm{O}}}\right) \mathrm{d} y_{\mathrm{H}_{2} \mathrm{O}}
$$

Derivation of the current efficiency with respect to $\lambda, y_{\mathrm{O}_{2}}^{\text {out }}$ and $y_{\mathrm{H}_{2} \mathrm{O}}$ followed by algebraic rearrangement led to:

$$
\frac{\mathrm{d} \Phi}{\Phi}=\frac{\mathrm{d} \lambda}{\lambda}+\frac{\mathrm{d} y_{\mathrm{O}_{2}}^{\text {out }}}{y_{\mathrm{O}_{2}}^{\text {out }}}\left[y_{\mathrm{O}_{2}}^{\text {out }}\left(\frac{1}{B}-\frac{1}{A y_{\mathrm{O}_{2}}^{\text {in }}}\right)\right]+\frac{\mathrm{d} y_{\mathrm{H}_{2} \mathrm{O}}}{y_{\mathrm{H}_{2} \mathrm{O}}}\left[y_{\mathrm{H}_{2} \mathrm{O}}\left(\frac{1}{B}-\frac{1}{A}\right)\right]
$$

with

$$
A=1-y_{\mathrm{H}_{2} \mathrm{O}}-\frac{y_{\mathrm{O}_{2}}^{\text {out }}}{y_{\mathrm{O}_{2}}^{\text {in }}}
$$

and

$$
B=1-y_{\mathrm{O}_{2}}^{\text {out }}-y_{\mathrm{H}_{2} \mathrm{O}}
$$

Factor $\lambda$ is linked to the molar flow rate of fed oxygen, which is proportional to the volume flow rate: the relative uncertainty of I can therefore be estimated by that for the inlet air flow rate. The flow meters employed for the measurements had a $1 \%$ relative uncertainty in a large range of flow rates, i.e. for flow rates larger than $2 \%$ of the full scale flow rate $Q_{\mathrm{air}}^{\max }$. Below this threshold value, larger uncertainty can be expected. The following expressions were then considered: 


$$
\begin{aligned}
& \frac{\Delta \lambda}{\lambda}=\frac{\Delta Q_{\mathrm{air}}^{\text {in }}}{Q_{\mathrm{air}}^{\text {in }}}=1 \% \frac{0.02 Q_{\mathrm{air}}^{\mathrm{max}}}{Q_{\mathrm{air}}^{\text {in }}} \text { for } Q_{\mathrm{air}}^{\text {in }}<0.02 Q_{\mathrm{air}}^{\mathrm{max}} \\
& \frac{\Delta \lambda}{\lambda}=\frac{\Delta Q_{\mathrm{air}}^{\text {in }}}{Q_{\mathrm{air}}^{\text {in }}}=1 \% \text { for } Q_{\mathrm{air}}^{\text {in }}>0.02 Q_{\mathrm{air}}^{\max }
\end{aligned}
$$

In practice, because of the flow rate scale considered, the relative uncertainty varied from 3 to $10 \%$.

Moreover, in spite of the replicate analysis in the gas chromatograph and the thorough calibration procedure, it can be estimated that the relative error in the analytical determination is near $1 \%$ :

$$
\frac{\Delta y_{\mathrm{O}_{2}}^{\text {out }}}{y_{\mathrm{O}_{2}}^{\text {out }}}=1 \%
$$

Finally, the uncertainty in $y_{\mathrm{H}_{2} \mathrm{O}}$ is due to uncertainty in the ambient temperature. Considering that this temperature was estimated within $1{ }^{\circ} \mathrm{C}$ and using Antoine's law (5), the relative uncertainty in the molar fraction of vapour could be estimated in the temperature range considered:

$$
\frac{\Delta y_{\mathrm{H}_{2} \mathrm{O}}}{y_{\mathrm{H}_{2} \mathrm{O}}}=4.5 \%
$$

Applications of relations (A2)-(A7) yielded estimates for the relative uncertainty on the current efficiency, in the range $2-30 \%$ for most cases.

\section{References}

[1] J. Winnick, "Electrochemical separation of Gases", in "Advances in Electrochemical Science and Engineering", edited by H. Gerischer and C.W. Tobias, Vol. 1, VCH, New-York (1990), 210-248.

[2] S.H. Langer and R.G. Haldemann, J. Phys. Chem. 68 (1964) 962-963.

[3] R.A. Wynveen and K.M. Montgomery, J. Electrochem. Soc. 114 (1967) 589-592.

[4] Y. Fujita, H. Nakamura, T. Muto, J. Appl. Electrochem. 16 (1986) 935-940.

[5] J.W. Harrison, ASME 75-ENAs-51 (1975).

[6] W.N. Lawless, US Patent N 4,462,891 (July 31, 1984); 4,547,277 (Oct. 15, 1985).

[7] L.G. Marianowski and R.J. Remick, US Patent N 4,589,296 (1989).

[8] M. Riecke, US Patent N 6,632,400 B2 (2003).

[9] A.C. Tseung, S.M. Jasem, J. Appl. Electrochem. 11 (1981) 209-215.

[10] E. Brillas, A. Maestro, M. Moratalla, J. Appl. Electrochem. 27 (1997) 83-92.

[11] S. Altmeyer, E. Favre, C. Bonnet, P. Carré, F. Lapicque « Etude de procédés pour application au flux gazeux d'un photobioréacteur de culture d'algues ", Report 08 GPS 155, Nancy (Jan. 2009) [in French].

[12] A. Pozio, M. De Franceco, A. Cemmi,F. Cardellini and L. Giorgi, J. Power Sources 105 (2002) 13-19.

(c) 2012 by the authors; licensee IAPC, Zagreb, Croatia. This article is an open-access article distributed under the terms and conditions of the Creative Commons Attribution license

(http://creativecommons.org/licenses/by/3.0/) (cc) EY 